\title{
THEORETICAL AND NUMERICAL ANALYSIS OF AN ALUMINUM FOAM SANDWICH STRUCTURE
}

\author{
${ }^{1}$ Alaa AL-FATLAWI, ${ }^{2}$ Károly JÁRMAI, ${ }^{3}$ György KOVÁCS ${ }^{*}$ \\ ${ }^{1,2,3}$ Faculty of Mechanical Engineering and Informatics, University of Miskolc \\ H-3515 Miskolc, Egyetemváros, Hungary \\ e-mail: ${ }^{1}$ vegyalaa@uni-miskolc.hu, ${ }^{2}$ jarmai@uni-miskolc.hu, ${ }^{3}$ altkovac@uni-miskolc.hu
}

Received 29 December 2019; accepted 9 April

\begin{abstract}
The aim of the research was to develop a new lightweight sandwich structure, which can be used for elements of air containers. The structure consists of aluminum foam core with fiber reinforced composite face-sheets. Nine different laminated glass or/and carbon fiber reinforced plastic face-sheet combinations were investigated. Finite element analysis of the sandwich structures was introduced. Single-objective optimization of the new sandwich structure was achieved for minimal weight. Five design constraints were considered: stiffness of the structure, face-sheet failure, core shear, face-sheet wrinkling, size constraints for design variables. The elaborated composite structure results significant weight savings due to low density.
\end{abstract}

Keywords: Sandwich structure, Fiber reinforced plastic face-sheet, Aluminum foam core, Structural optimization, Minimum weight

\section{Introduction}

The purpose of the study is the design of a lightweight structure consists of fiber reinforced plastic face-sheets (nine different laminated glass fiber or/and carbon fiber reinforced plastic face-sheet combinations) and aluminum foam core. The fiber reinforced plastic face-sheets and the core has a small density and high specific stiffness, which can meet the stiffness requirements and reduce the weight of the sandwich structure. The elaborated structural model can be used for manufacturing of walls, floor and roof of containers to fulfill the requirements of shipping and airlines

\footnotetext{
${ }^{*}$ Corresponding Author
} 
carriers. The aim of the application of lightweight containers is to provide a huge savings in weight compared to conventional steel containers, which results in lower fuel consumption of transport vehicles and less environmental damage.

The sandwich structures consist of composite face-sheets and foam core are widely utilized in many engineering applications such as aerospace and automotive applications due to its high performance like bending stiffness and strength to weight ratios [1]. Huang and Alspaugh [2] introduced a method to determine the minimum weight of sandwich beams. The most common applied design constraints related to bending stress, shear stress and deflection, where the face-sheets thickness and the core thickness are design variables. Gibson [3] described an analytical method to find the optimum thickness and density of the foam core sandwich beam to minimize the weight. Gibson and Triantafillou described the way to minimize the weight of a sandwich beam with a foam core. The analysis gave the optimum core and face-sheets thicknesses and the density of the core [4]. In the books of Zenkert and Bitzer several methods and algorithms are described to minimize the weight of sandwich structures with symmetrical and unsymmetrical face-sheets and subjected to bending and torsional stiffness requirement [5]-[6]. Kota and Jarmai show also a very well scalable discrete firefly algorithm. The built in general reduced gradient and evolutionary algorithms of the Excel solver are also compared solving similar problems [7]. Hazim and Jarmai estimate the minimum structural dimensions of robot arms [8]. Many researchers have studied the influence of hybrid composite materials on mechanical properties of the structure [9]. Dong and Davies studied the flexural behavior of hybrid composites consist of glass and carbon fibers [10]. The effect of hybrid observed when the natural fiber reinforced plastics layers built into the conventional sandwich panels with aluminum face-sheets [11]. Lot of algorithms is available for optimization of composite laminated structures [12]. A few studies included the cost of the sandwich structure as a design aim [13].

\section{A new sandwich structural model}

The newly constructed sandwich structure consists of aluminum $(A l)$ foam core with laminated glass fiber and/or carbon fiber reinforced plastic face-sheets, see Fig. 1. The dimensions and weights of the core and face-sheets used in this structure are given in Table I. The technical notes of the flexure model program for symmetrical sandwich structures were clarified. The norm of the model is MIL-STD-401B [14].

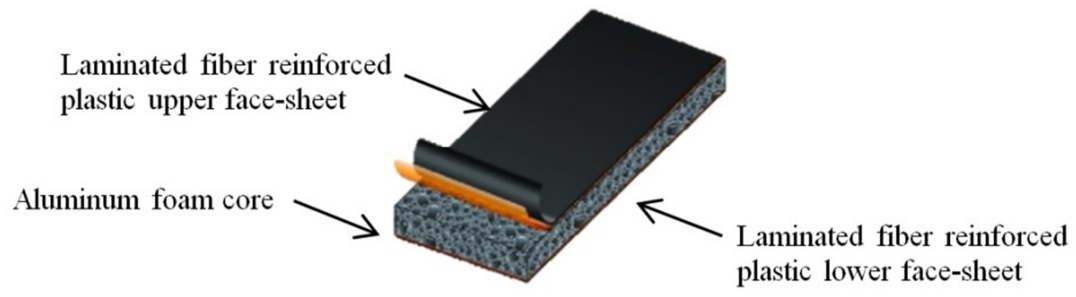

Fig. 1. Aluminum foam core sandwich structure with laminated composite face-sheets 
Table I

Data relating to the structural elements of the investigated sandwich structure

\begin{tabular}{|l|c|c|c|c|c|c|c|c|l|l|l|}
\hline \multirow{2}{*}{ Fibers } & \multicolumn{4}{|l|}{ Dimension } & \multicolumn{1}{|c|}{ Density } & \multicolumn{2}{|l|}{ Weight } \\
& \multicolumn{1}{l}{} & $b$ & $h$ & $t_{c}$ & $t_{f}$ & $\rho_{c}$ & $\rho_{g}$ & $\rho_{c r}$ & $W_{\text {core }}$ & $W_{\text {skin }}$ & $W_{t}$ \\
\hline Unit & $\mathrm{mm}$ & $\mathrm{mm}$ & $\mathrm{mm}$ & $\mathrm{mm}$ & $\mathrm{mm}$ & $\mathrm{kg} / \mathrm{m}^{3}$ & $\mathrm{~kg} / \mathrm{m}^{3}$ & $\mathrm{~kg} / \mathrm{m}^{3}$ & $\mathrm{~kg}$ & $\mathrm{~kg}$ & $\mathrm{~kg}$ \\
\hline E-glass & 1000 & 100 & 24 & 20 & 2 & 300 & & & 0.6 & 0.38 & 1.36 \\
Carbon & 1000 & 100 & 24 & 20 & 2 & 300 & 1900 & 1600 & 0.6 & 0.32 & 1.24 \\
Hybrid & 1000 & 100 & 24 & 20 & 2 & 300 & & & 0.6 & 0.35 & 1.30 \\
\hline
\end{tabular}

where $l$ is the length; $b$ is the width of the sandwich structure; $\rho_{g}$ is the density of the E-glass fiber/epoxy resin laminate; $\rho_{c r}$ is the density of the carbon fiber/epoxy resin laminate; $\rho_{c}$ is the density of the foam core; $t_{f}$ is the thickness of the face-sheet; $t_{c}$ is the thickness of the foam core and $h$ is the total thickness of the sandwich structure. $W_{\text {core }}$ is the weight of the foam core; $W_{\text {skin }}$ is the weight of the face-sheet; $W_{t}$ is the total weight of the sandwich structure.

\subsection{Aluminum foam core}

The foam core is closed cell formed from $\mathrm{Al}$ alloy. The mechanical properties of the core make it ideal for several applications. These properties include high strength and stiffness to weight ratio and high energy absorption as shown in Table II, [15].

Table II

Data of Cymat A35620SC 030SS stabilized aluminum foam

\begin{tabular}{|l|l|l|l|}
\hline$E$ & Compressive modulus & 1200 & $\mathrm{MPa}$ \\
$v$ & Poission's ratio & 0.33 & --- \\
$G$ & Shear modulus & 1000 & $\mathrm{MPa}$ \\
$\sigma$ & Compressive strength & 4 & $\mathrm{MPa}$ \\
$\tau$ & Shear strength & 1 & $\mathrm{MPa}$ \\
$\rho$ & Density & 300 & $\mathrm{~kg} / \mathrm{m}^{3}$ \\
\hline
\end{tabular}

\subsection{Laminated fiber reinforced plastic face-sheets}

Nine different sandwich constructions were studied, which consist of $A l$ foam core with upper and lower skin face-sheets. The laminated glass fiber and/or carbon fiber reinforced plastic face-sheets were symmetrical concerning to the mid-plane of the sandwich structure. Every skin face-sheet composed of 4-layers. The fiber orientation in the face-sheets is having cross ply $\left(0^{\circ}, 90^{\circ}\right)$ and angle ply $\pm 45^{\circ}$. Table III includes the mechanical properties of the different composite layers.

E-glass fiber/epoxy resin face-sheets

Three constructions were investigated: Al foam core sandwich structure with 4layers in the upper and 4-layers in the lower skin face-sheets made of fabric of E-glass fiber/epoxy resin with fiber orientation $\left(0^{\circ}, 90^{\circ}, 0^{\circ}, 90^{\circ}\right),\left(0^{\circ}, 90^{\circ},+45^{\circ},-45^{\circ}\right)$ and $\left(+45^{\circ},-45^{\circ},+45^{\circ},-45^{\circ}\right)$. 
Table III

Mechanical properties of composite materials [16]

\begin{tabular}{|l|l|l|l|l|}
\hline Fiber $0^{\circ}, 90^{\circ}$ fabric to loading axis, Dry, Room Temperature, $V_{f}=50 \%$ \\
\hline Property & Symbol & E-glass & Carbon & Units \\
Young's Modulus $0^{\circ}$ & $E_{1}$ & 25 & 70 & $\mathrm{GPa}$ \\
Young's Modulus $90^{\circ}$ & $E_{2}$ & 25 & 70 & $\mathrm{GPa}$ \\
In-plane Shear Modulus & $G_{12}$ & 4 & 5 & $\mathrm{GPa}$ \\
Major Poisson's Ratio & $v_{12}$ & 0.2 & 0.1 & ---- \\
Ultimate Tensile Strength $0^{\circ}$ & $X_{t}$ & 440 & 600 & $\mathrm{MPa}$ \\
Ultimate Compression Strength $0^{\circ}$ & $X_{c}$ & 425 & 570 & $\mathrm{MPa}$ \\
Ultimate Tensile Strength 90 & $Y_{t}$ & 440 & 600 & $\mathrm{MPa}$ \\
Ultimate Compression Strength $90^{\circ}$ & $Y_{c}$ & 425 & 570 & $\mathrm{MPa}$ \\
Ultimate In-plane Shear Strength & $S$ & 40 & 90 & $\mathrm{MPa}$ \\
\hline Fiber $\pm 45^{\circ}$ to loading axis, Dry, Room Temperature, $V_{f}=50 \%$ (fabric) \\
\hline Property & Symbol & $\mathrm{E}-$ glass & Carbon & $\mathrm{Units}$ \\
Longitudinal Modulus & $E_{1}$ & 12.2 & 19.1 & $\mathrm{GPa}$ \\
Transverse Modulus & $E_{2}$ & 12.2 & 19.1 & $\mathrm{GPa}$ \\
In-plane Shear Modulus & $G_{12}$ & 8 & 30 & $\mathrm{GPa}$ \\
Poisson's Ratio & $v_{12}$ & 0.53 & 0.74 & ---- \\
Tensile Strength & $X_{t}$ & 120 & 120 & $\mathrm{MPa}$ \\
Compression Strength & $X_{c}$ & 120 & 120 & $\mathrm{MPa}$ \\
In-plane Shear Strength & $S$ & 150 & 310 & $\mathrm{MPa}$ \\
\hline
\end{tabular}

Carbon fiber/epoxy resin face-sheets

Three constructions were investigated: $A l$ foam core sandwich structure with 4layers in the upper and 4-layers in the lower skin face-sheets made of fabric of carbon fiber/epoxy resin with fiber orientation $\left(0^{\circ}, 90^{\circ}, 0^{\circ}, 90^{\circ}\right),\left(0^{\circ}, 90^{\circ},+45^{\circ},-45^{\circ}\right)$ and $\left(+45^{\circ},-45^{\circ},+45^{\circ},-45^{\circ}\right)$.

\section{Hybrid face-sheets (combination of glass and carbon fiber layers)}

Three constructions were investigated: Al foam core sandwich structure with 4layers in the upper and 4-layers in the lower skin face-sheets (outer two layers of carbon and inner two layers of E-glass laminas). The hybrid face-sheet is the combination of carbon fiber and E-glass fiber/epoxy resin laminas with different fiber orientations: $\left(0^{\circ}\right.$, $\left.90^{\circ}, 0^{\circ}, 90^{\circ}\right),\left(0^{\circ}, 90^{\circ},+45^{\circ},-45^{\circ}\right)$ and $\left(+45^{\circ},-45^{\circ},+45^{\circ},-45^{\circ}\right)$.

\section{Finite element analysis of the investigated sandwich structures}

In this study, the deflection, skin stress and core shear stress were calculated numerically by using finite element analysis (Digimat-HC) program for 4-point flexural model, where $P$ is the applied load; $\delta$ is the deflection of sandwich structure; $\sigma_{\text {skin }}$ is the skin stress and $\tau_{\text {core }}$ is the core shear stress. Numerical results of the finite element analysis can be seen in (Table IV - Table VI); and in (Fig. 2 - Fig. 4). The introduction 
of print screens of the finite element analysis results for all of nine constructions is not possible in this study due to space constraints.

\section{Table IV}

Analytical and numerical results for aluminum foam core sandwich structure with E-glass fiber/epoxy resin face-sheets with different fiber orientations $\left(0^{\circ}, 90^{\circ}\right.$ and $\left.\pm 45^{\circ}\right)$

\begin{tabular}{|c|c|c|c|c|c|c|c|c|c|}
\hline E-glass fiber & \multicolumn{4}{|c|}{ Numerical results } & \multicolumn{3}{|c|}{ Optimum results } & \multirow{2}{*}{$W_{t}$} & \multirow{2}{*}{$W_{\text {red. }}$} \\
\hline Symbol & $P$ & $\delta$ & $\sigma_{\text {skin }}$ & $\tau_{\text {core }}$ & $t_{c o p t}$ & $t_{\text {fopt }}$ & $W_{\min }$ & & \\
\hline Unit & $\mathrm{N}$ & $\mathrm{mm}$ & $\mathrm{MPa}$ & $\mathrm{MPa}$ & $\mathrm{mm}$ & $\mathrm{mm}$ & $\mathrm{kg}$ & $\mathrm{kg}$ & $\%$ \\
\hline $0^{\circ}, 90^{\circ}, 0^{\circ}, 90^{\circ}$ & 1000 & 9.877 & 25.6 & 1.08 & 23.224 & 0.998 & 1.076 & 1.36 & 20.88 \\
\hline $0^{\circ}, 90^{\circ}, \pm 45^{\circ}$ & 1000 & 10.949 & 28.4 & 1.18 & 23.244 & 1.012 & 1.081 & 1.36 & 20.51 \\
\hline $\pm 45^{\circ}, \pm 45^{\circ}$ & 1000 & 12.597 & 25.1 & 1.36 & 23.224 & 0.984 & 1.070 & 1.36 & 21.32 \\
\hline
\end{tabular}

Table V

Analytical and numerical results for aluminum foam core sandwich structure with carbon fiber/epoxy resin face-sheets with different fiber orientations $\left(0^{\circ}, 90^{\circ}\right.$ and $\left.\pm 45^{\circ}\right)$

\begin{tabular}{|c|c|c|c|c|c|c|c|c|c|}
\hline Carbon fiber & \multicolumn{4}{|c|}{ Numerical results } & \multicolumn{3}{|c|}{ Optimum results } & \multirow{2}{*}{$W_{t}$} & \multirow{2}{*}{$W_{\text {red. }}$} \\
\hline Symbol & $P$ & $\delta$ & $\sigma_{\text {skin }}$ & $\tau_{\text {core }}$ & $t_{\text {copt }}$ & $t_{\text {fopt }}$ & $W_{\min }$ & & \\
\hline Unit & $\mathrm{N}$ & $\mathrm{mm}$ & $\mathrm{MPa}$ & $\mathrm{MPa}$ & $\mathrm{mm}$ & $\mathrm{mm}$ & $\mathrm{kg}$ & $\mathrm{kg}$ & $\%$ \\
\hline $0^{\circ}, 90^{\circ}, 0^{\circ}, 90^{\circ}$ & 1000 & 3.746 & 26.6 & 0.54 & 21.204 & 1.110 & 0.991 & 1.24 & 20.08 \\
\hline $0^{\circ}, 90^{\circ}, \pm 45^{\circ}$ & 1000 & 4.281 & 29.3 & 0.57 & 21.204 & 0.998 & 0.955 & 1.24 & 22.98 \\
\hline $\pm 45^{\circ}, \pm 45^{\circ}$ & 1000 & 5.502 & 26.4 & 0.67 & 19.183 & 0.970 & 0.886 & 1.24 & 28.54 \\
\hline
\end{tabular}

\section{Table VI}

Analytical and numerical results for aluminum foam core sandwich structure with hybrid facesheets with different fiber orientations $\left(0^{\circ}, 90^{\circ}\right.$ and $\left.\pm 45^{\circ}\right)$

\begin{tabular}{|l|l|l|l|l|l|l|l|l|l|}
\hline Hybrid & \multicolumn{4}{|l|}{ Numerical results } & \multicolumn{3}{|c|}{ Optimum results } & \multirow{2}{*}{$W_{t}$} & \multirow{2}{*}{$W_{\text {red. }}$} \\
\hline Symbol & $P$ & $\delta$ & $\sigma_{\text {skin }}$ & $\tau_{\text {core }}$ & $t_{\text {c opt }}$ & $t_{\text {f opt }}$ & $W_{\text {min }}$ & & \\
\hline Unit & $\mathrm{N}$ & $\mathrm{mm}$ & $\mathrm{MPa}$ & $\mathrm{MPa}$ & $\mathrm{mm}$ & $\mathrm{mm}$ & $\mathrm{kg}$ & $\mathrm{kg}$ & $\%$ \\
\hline $0^{\circ}, 90^{\circ}, 0^{\circ}, 90^{\circ}$ & 1000 & $\mathbf{5 . 1 8 5}$ & 37.6 & $\mathbf{0 . 6 6}$ & 23.224 & 1.181 & 1.110 & 1.30 & 14.61 \\
$0^{\circ}, 90^{\circ}, \pm 45^{\circ}$ & 1000 & 5.461 & 39.6 & 0.68 & 23.224 & 1.279 & 1.144 & 1.30 & 12.00 \\
$\pm 45^{\circ}, \pm 45^{\circ}$ & 1000 & 9.708 & $\mathbf{3 0 . 9}$ & 1.07 & 23.224 & 1.096 & $\mathbf{1 . 0 8 0}$ & 1.30 & 16.92 \\
\hline
\end{tabular}

\section{Minimum weight optimization of the investigated sandwich structure}

The optimization method for the newly constructed sandwich structure (Fig. 1) was elaborated. The fibers orientation in the face-sheets is having angles of cross ply $0^{\circ}, 90^{\circ}$ and angle ply $\pm 45^{\circ}$. The optimal design variables were face-sheet thickness $t_{f}$ and core thickness $t_{c}$ to minimize the weight of the sandwich structures, Eqs. (1)-(3). During the optimization five design constraints were taken into consideration, Eqs. (4)-(8). The equations of the optimization problem are listed below [17]. The classical lamination theory and Tsai-Hill criteria of the first ply failure used to calculate the mechanical 
properties of the laminated face-sheet [18]. The constraints of the optimization problem are stiffness, face-sheet failure, core shear, face-sheet wrinkling.

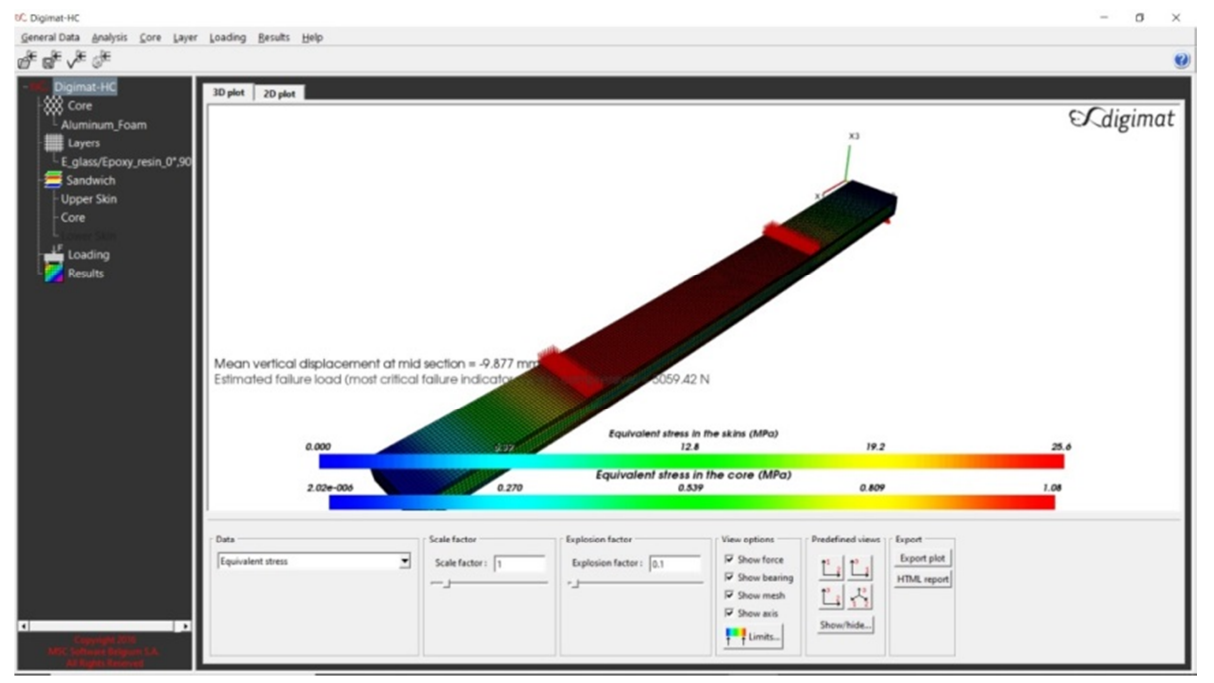

Fig. 2. Numerical results by using (Digimat-HC) program; flexural model of the sandwich structure consists of E-glass fiber/epoxy resin face-sheets $\left(0^{\circ}, 90^{\circ}, 0^{\circ}, 90^{\circ}\right)$ with $\mathrm{Al}$ foam core

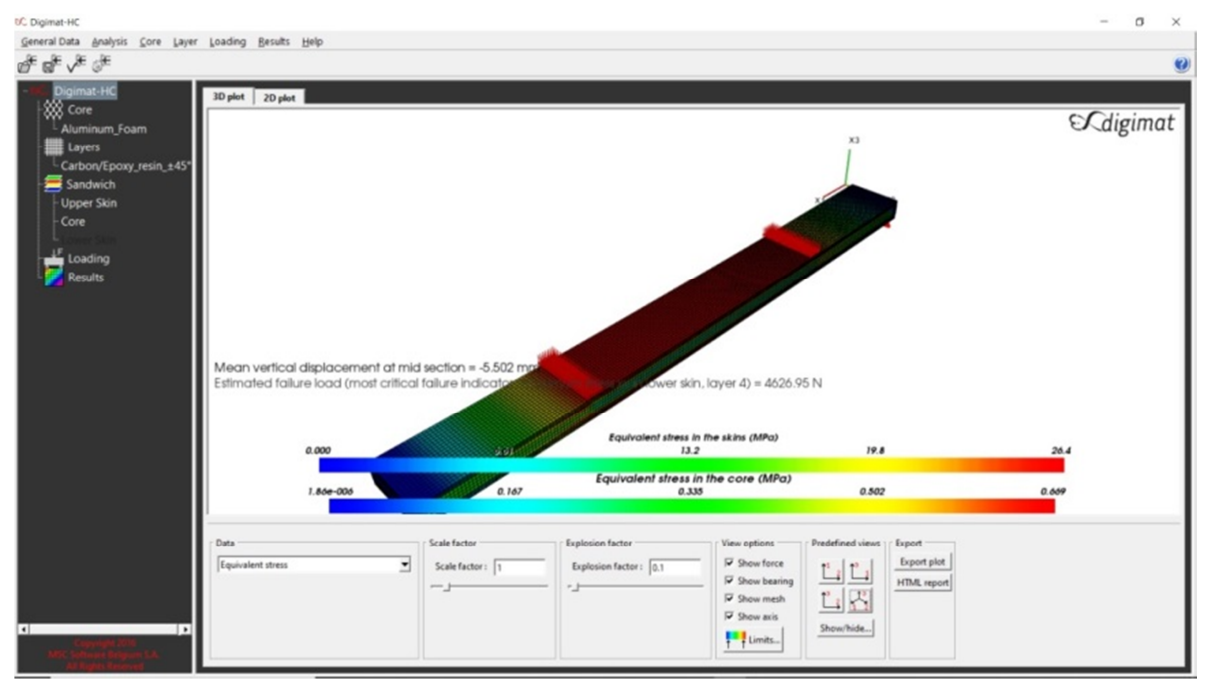

Fig. 3. Numerical results by using (Digimat-HC) program; flexural model of the sandwich structure consists of carbon fiber/epoxy resin face-sheets $\left( \pm 45^{\circ}, \pm 45^{\circ}\right)$ with $\mathrm{Al}$ foam core

The sandwich structure stiffness, the maximum load of face-sheet failure, core shear and skin wrinkling for every core thickness and face-sheet thickness were calculated. 
With all these data, for every step, the minimum face-sheet thickness was calculated that accomplishes the load defined and the stiffness required, Eq. (4). The software calculates the minimum weight condition for the sandwich structure, which corresponds to the face-sheet thickness and the core thickness. This software is a modified version of the software in the composite sandwich optimizer 2017, GitHub, Inc [19]. The program was developed to fit with the flexure model. The results of numerical (Digimat-HC) program were used as inputs to achieve the desired results (maximum deformation $\delta_{\max }$ and maximum load $P_{\max }$ ).

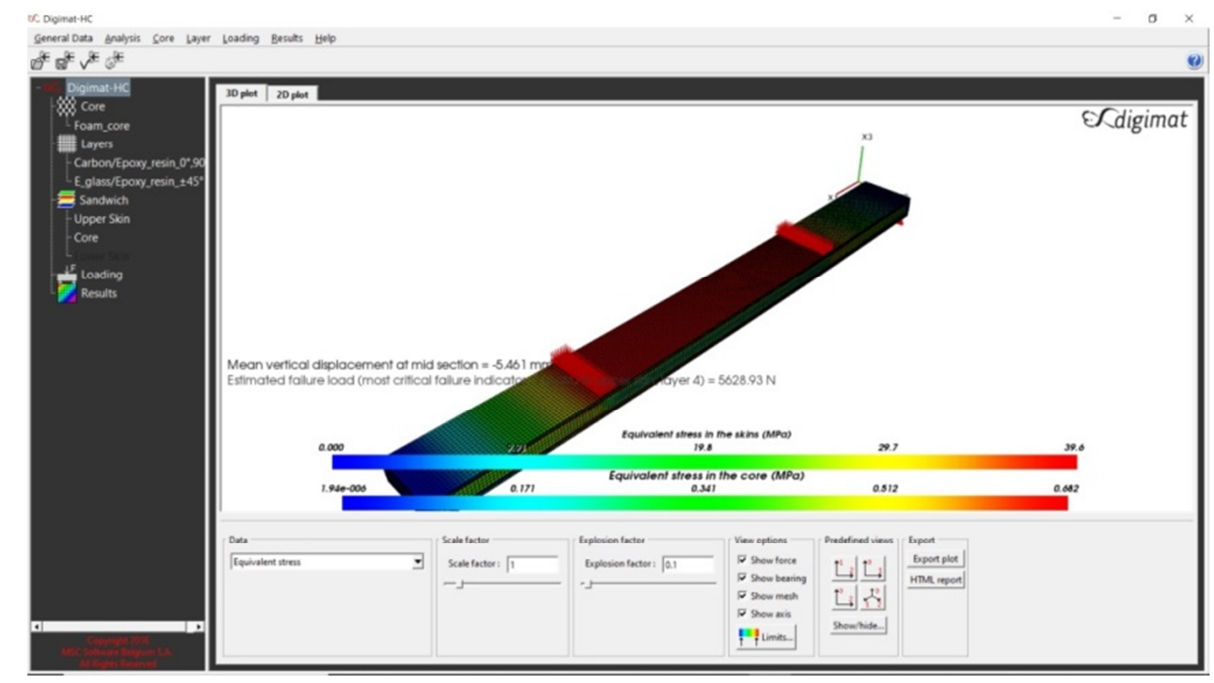

Fig. 4. Numerical results by using (Digimat-HC) program; flexural model of the sandwich structure consists of hybrid face-sheets $\left(0^{\circ}, 90^{\circ},+45^{\circ},-45^{\circ}\right)$ with $A l$ foam core

\subsection{Total weight objective functions}

Weight of E-glass fiber/epoxy resin face-sheets with aluminum foam core:

$$
W_{t}=W_{f}+W_{c}=2 W_{g}+W_{c}=2 \rho_{g} t_{g} l b+\rho_{c} t_{c} l .
$$

Weight of carbon fiber/epoxy resin face-sheets with aluminum foam core:

$$
W_{t}=W_{f}+W_{c}=2 W_{c r}+W_{c}=2 \rho_{c r} t_{c r} l b+\rho_{c} t_{c} l b .
$$

Weight of hybrid face-sheets with aluminum foam core:

$$
W_{t}=W_{f}+W_{c}=2\left(W_{g}+W_{c r}\right)+W_{c}=2\left(\rho_{g} t_{g} l b+\rho_{c r} t_{c r} l b\right)+\rho_{c} t_{c} l b .
$$

\subsection{Design constraint}

Constraint for the stiffness of the sandwich structure:

The minimum stiffness of sandwich structure $(E I)_{\min }$ was calculated by using given data from and numerical results (Digimat-HC) $(\delta$ and $P)$. 


$$
(E I)_{\min }=\frac{P l^{3}}{B_{3} \delta} \leq D=\frac{E_{f} t_{f} h^{2} b}{2}, h=t_{c}+t_{f} .
$$

Constraint for face-sheets failure

$$
P_{a c t} \leq P_{f f}=\frac{\sigma_{f} b t_{f} h}{B_{1} l} .
$$

Constraint for core shear

$$
P_{a c t} \leq P_{c s}=\frac{\tau_{c} b h}{B_{2}} .
$$

Constraint for face-sheet wrinkling

$$
P_{a c t} \leq P_{w r}=\frac{b t_{f} h}{2 B_{1} l\left[E_{C} G_{c} E_{f}\right]^{1 / 3}} .
$$

Size constraint for design variables

$$
10 \mathrm{~mm} \leq t_{\text {copt }} \leq 100 \mathrm{~mm}, \quad \text { and } \quad 0.1 \mathrm{~mm} \leq t_{\text {fopt }} \leq 5 \mathrm{~mm},
$$

where $B_{1}=\frac{1}{8}, B_{2}=\frac{1}{2}, B_{3}=\frac{768}{11}$, and $P_{a c t}=1000 \mathrm{~N}$ (Simply supported, flexural model).

\subsection{Results of the optimization}

The final results are optimum core thickness $\left(t_{c \text { opt }}\right)$, optimum face thickness $\left(t_{f \text { opt }}\right)$ and minimum weight $\left(W_{\text {min }}\right)$ as shown in (Table IV - Table VI) and (Fig. 5 - Fig. 7). The optimization results of all 9 constructions are not possible in this study due to space constraints.

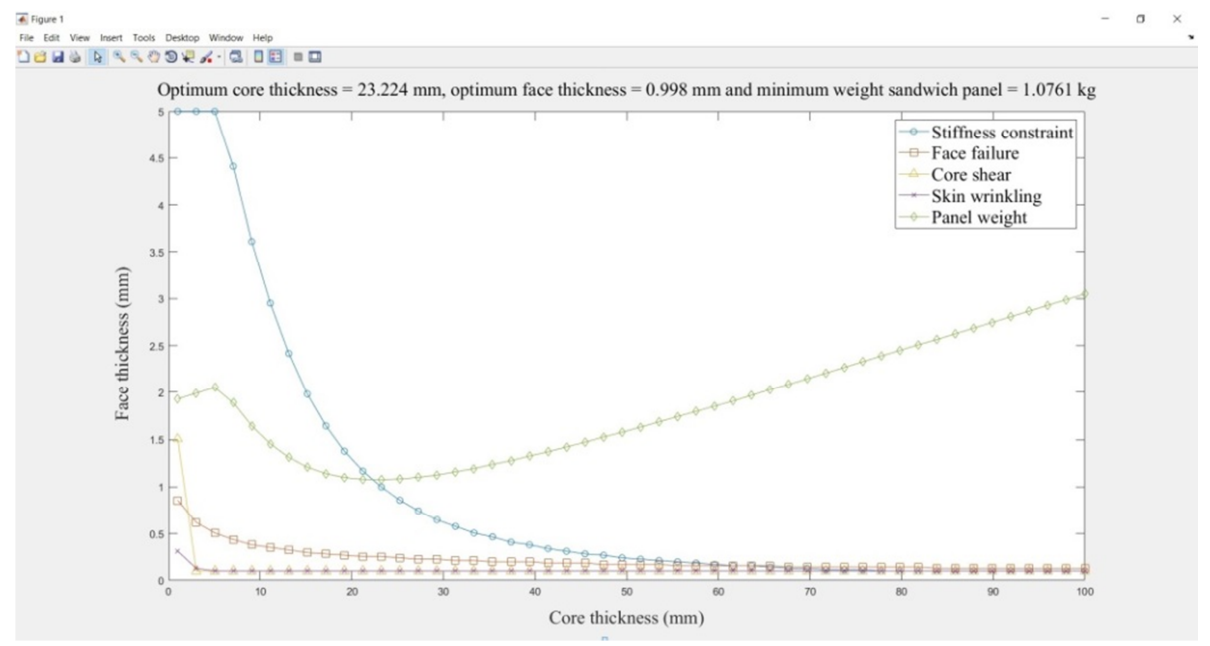

Fig. 5. Theoretical results by using MATLAB program, flexure model, the sandwich structure consists of E-glass fiber/epoxy resin face-sheets $\left(0^{\circ}, 90^{\circ}, 0^{\circ}, 90^{\circ}\right)$ with $\mathrm{Al}$ foam core 


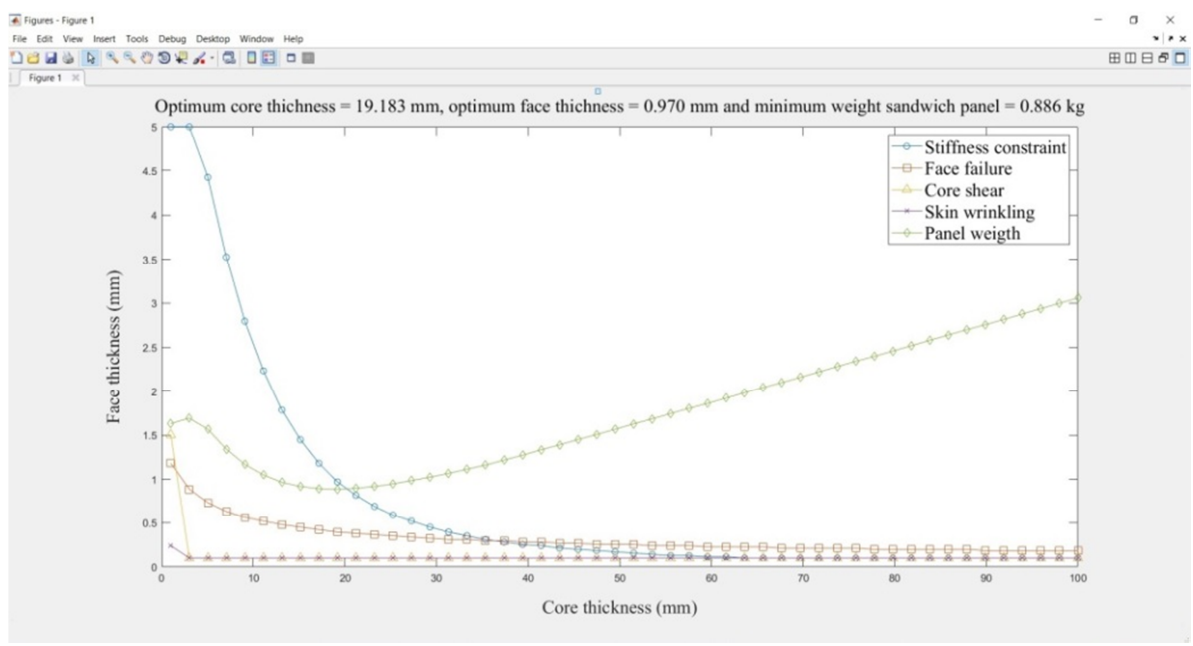

Fig. 6. Theoretical results by using MATLAB program, flexure model, the sandwich structure consists of carbon fiber/epoxy resin face-sheets $\left(+45^{\circ},-45^{\circ},+45^{\circ},-45^{\circ}\right)$ with $\mathrm{Al}$ foam core

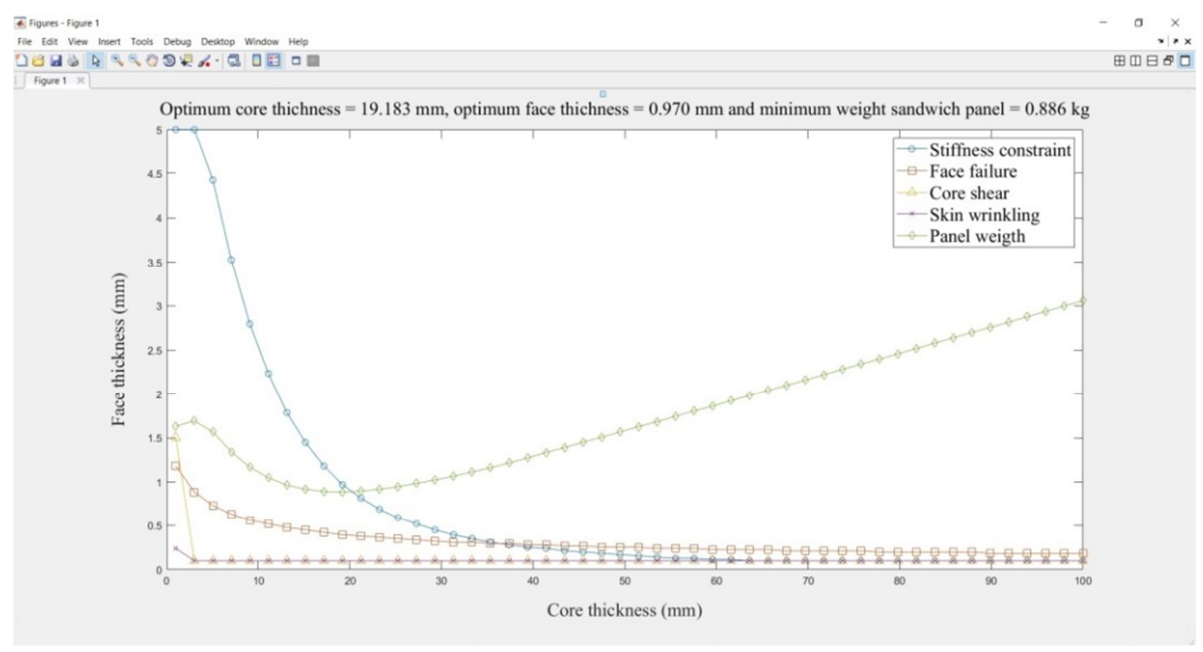

Fig. 7. Theoretical results by using MATLAB program, flexure model, the sandwich structure consist of hybrid face-sheets $\left(0^{\circ}, 90^{\circ},+45^{\circ},-45^{\circ}\right)$ with $\mathrm{Al}$ foam core

\section{Evaluation of the results}

\subsection{Numerical results in case of different types of laminated composite face-sheets}

According to the numerical results of sandwich structures with aluminum foam core and different types of composite face-sheets, as shown in (Table IV - Table VI) and (Fig. 2 - Fig. 4), the deflection and core shear stress of the sandwich structures with 
carbon fiber/epoxy resin face-sheet are less than the deflection and core shear stress of the sandwich structures with hybrid and E-glass fiber/epoxy resin face-sheet respectively, because of the carbon fiber having higher stiffness-to-weight ratio compared to E-glass fiber. The skin stress of the sandwich structures with E-glass fiber/epoxy resin face-sheet is less than the skin stress of the sandwich structures with carbon fiber/epoxy resin and hybrid face-sheet respectively, because of the E-glass fiber having high strength-to-weight ratio and more flexible compared to carbon fiber.

\subsection{Numerical results in case of different fiber orientations of composite layers}

The numerical results of sandwich structures with aluminum foam core and different fiber orientations of composite face-sheets cross ply $\left(0^{\circ}, 90^{\circ}\right)$ and angle ply $\left( \pm 45^{\circ}\right)$ are the following: the deflection and core shear stress of the sandwich structures with facesheet fiber orientation $\left(0^{\circ}, 90^{\circ}, 0^{\circ}, 90^{\circ}\right)$ are less than the deflection and core shear stress of the sandwich structures with face-sheets fiber orientation $\left(0^{\circ}, 90^{\circ},+45^{\circ},-45^{\circ}\right)$ and fiber orientation $\left(+45^{\circ},-45^{\circ},+45^{\circ},-45^{\circ}\right)$ respectively, because of the fiber with cross ply orientation $\left(0^{\circ}, 90^{\circ}, 0^{\circ}, 90^{\circ}\right)$ having higher young modulus of elasticity and stiffness compare with angle ply $\left(+45^{\circ},-45^{\circ},+45^{\circ},-45^{\circ}\right)$. The skin stress of the sandwich structures with fiber orientation $\left(+45^{\circ},-45^{\circ},+45^{\circ},-45^{\circ}\right)$ of face-sheet are less than the skin stress of the sandwich structures with fiber orientation $\left(0^{\circ}, 90^{\circ}, 0^{\circ}, 90^{\circ}\right)$ and fiber orientation $\left(0^{\circ}, 90^{\circ},+45^{\circ},-45^{\circ}\right)$.

\subsection{Theoretical results in case of different types of laminated composite face-sheets}

According to the theoretical results, as shown in (Table IV - Table VI) and (Fig. 5 Fig. 7), the weight of the sandwich structures with carbon fiber/epoxy resin face-sheet is smaller than the weight of the sandwich structures with E-glass fiber/epoxy resin and hybrid of face-sheets.

\subsection{Theoretical results in case of different fiber orientations of composite layers}

According to the theoretical results of sandwich structures with aluminum foam core and different fiber orientation of composite materials face-sheet cross ply $\left(0^{\circ}, 90^{\circ}\right)$ and angle ply $\pm 45^{\circ}$, the weight of the sandwich structure with fiber orientation $\left(+45^{\circ},-45^{\circ}\right.$, $+45^{\circ},-45^{\circ}$ ) of face-sheet is less than the weight of the sandwich structures with fiber orientation $\left(0^{\circ}, 90^{\circ}, 0^{\circ}, 90^{\circ}\right)$ and fiber orientation $\left(0^{\circ}, 90^{\circ},+45^{\circ},-45^{\circ}\right)$.

\section{Conclusions}

The aim of the study was to develop a new sandwich structure, which can be used for manufacturing of walls, floor and roof of lightweight containers. The aim of the application of lightweight containers is to provide significant weight savings compared to conventional steel containers, which results in lower fuel consumption of transport vehicles and less environmental damage.

The new sandwich structure consists of aluminum foam core with upper and lower composite face-sheets. Nine different laminated glass fiber or/and carbon fiber 
reinforced plastic face-sheet combinations were investigated. In the study the finite element analysis of the investigated sandwich structures was introduced.

The optimization method was also elaborated for the new sandwich structure. The objective function was the total weight of the structure and five design constraints were taken into consideration, which were the following: total stiffness of the structure; facesheet failure; core shear; face-sheet wrinkling and size constraint for design variables.

Single-objective optimization of the new sandwich structural model was achieved for minimal weight. In the case study the optimal structure, which ensures the minimal weight of the sandwich structure is a carbon fiber/epoxy laminated face-sheet with 4 layers, with fiber orientation $\left(+45^{\circ},-45^{\circ},+45^{\circ},-45^{\circ}\right)$ and $\mathrm{Al}$ foam core, which thickness is $19.183 \mathrm{~mm}$. This optimal $\mathrm{Al}$ foam sandwich structure provides $28.54 \%$ weight saving compared to the original structure.

It can be concluded based on the results of the research, that the application of the elaborated sandwich structure can be suggested in those applications where weight saving is the most important design aim.

\section{Acknowledgements}

The described article was carried out as part of the EFOP-3.6.1-16-2016-00011 'Younger and Renewing University - Innovative Knowledge City - institutional development of the University of Miskolc aiming at intelligent specialization' project implemented in the framework of the Szechenyi 2020 program. The realization of this project is supported by the European Union, co-financed by the European Social Fund.

\section{Open Access statement}

This is an open-access article distributed under the terms of the Creative Commons Attribution 4.0 International License (https://creativecommons.org/licenses/by/4.0/), which permits unrestricted use, distribution, and reproduction in any medium, provided the original author and source are credited, a link to the CC License is provided, and changes - if any - are indicated. (SID_1)

\section{References}

[1] Li X., Li G., Wang C. H., You M.. Optimum design of composite sandwich structures subjected to combined torsion and bending loads, Applied Composite Materials, Vol. 19, No. 3-4, 2012, pp. 315-331.

[2] Huang S., Alspaugh D. Minimum weight sandwich beam design, AIAA Journal, Vol. 12, No. 12, 1974, pp. 1617-1618.

[3] Gibson L. J. Optimization of stiffness in sandwich beams with rigid foam cores, Materials Science and Engineering, Vol. 67, No. 2, 1984, pp. 125-135.

[4] Triantafillou T. C., Gibson, L. J. Minimum weight design of foam core sandwich panels for a given strength, Materials Science and Engineering, Vol. 95, 1987, pp. 55-62.

[5] Zenkert D. An introduction to sandwich construction, Engineering Materials Advisory Services, Emas Publishing, London, 1995. 
[6] Bitzer T. N. Honeycomb technology: Materials, esign, Manufacturing, Applications and Testing, London, Chapman \& Hall, 1997.

[7] Kota L., Jármai K. Efficient algorithms for optimization of objects and systems, Pollack Periodica, Vol. 9, No. 1, 2014, pp. 121-132.

[8] Hazim N., Jármai K. Kinematic-based structural optimization of robots, Pollack Periodica, Vol. 14, No. 3, 2019, pp. 213-222.

[9] Giancaspro J. W., Papakonstantinou C. G., Balaguru P. N. Flexural response of inorganic hybrid composites with E-glass and carbon fibers, Engineering Materials and Technology, Vol. 132, No. 2, 2010, pages 1-8.

[10] Dong C, Davies I. J. Optimal design for the flexural behavior of glass and carbon fiber reinforced polymer hybrid composites, Materials and Design, Vol. 37, 2012, pp. 450-457.

[11] Fajrin J., Zhuge Y., Bullen, F., Wang H. Significance analysis of flexural behavior of hybrid sandwich panels, Open Journal of Civil Engineering, Vol. 3, No. 3B, 2013, pp. 1-7.

[12] Rodrigues G. P., Guedes J. M., Folgado J. O. Combined topology and stacking sequence optimization of composite laminated structures for structural performance measures, In 4th Engineering Optimization Conference, Lisbon, Portugal, 8-11 September 2014, pp. 971-976.

[13] Kassapoglou C. Simultaneous cost and weight minimization of composite stiffened panels under compression and shear, Composites, Part A: Applied Science and Manufacturing, Vol. 28, No. 5, 1997, pp. 419-435.

[14] Mechanical testing of sandwich panels, Technical notes, 2007, https://www.hexcel.com/user_area/content_media/raw/SandwichPanels_global.pdf (last visited 20 September 2019).

[15] Cymat stabilized aluminium foam, http://www.matweb.com/search/datasheet.aspx?Mat GUID=bdd72d2af76c4e379ff82766b747ff9a\&ckck=1, (last visited 20 September 2019).

[16] Composite materials engineering specialists in carbon fiber, 2009, $\mathrm{http} / / /$ www.performance-composites.com/carbonfibre/mechanicalproperties_2.asp, (last visited 20 September 2019).

[17] Honeycomb sandwich design technology, 2007, https://www.hexcel.com/user_area/ content_media/raw/Honeycomb_Sandwich_Design_Technology.pdf, (last visited 15 September 2019).

[18] Kollár L. P., Springer G. S. Mechanics of composite structures, 2003.

[19] Composite sandwich optimizer, 2017, https://github.com/dinospiller/Composite-SandwichOptimizer (last visited 5 September 2019). 